\title{
ENTREVISTA
}

\section{Wellington Nogueira}

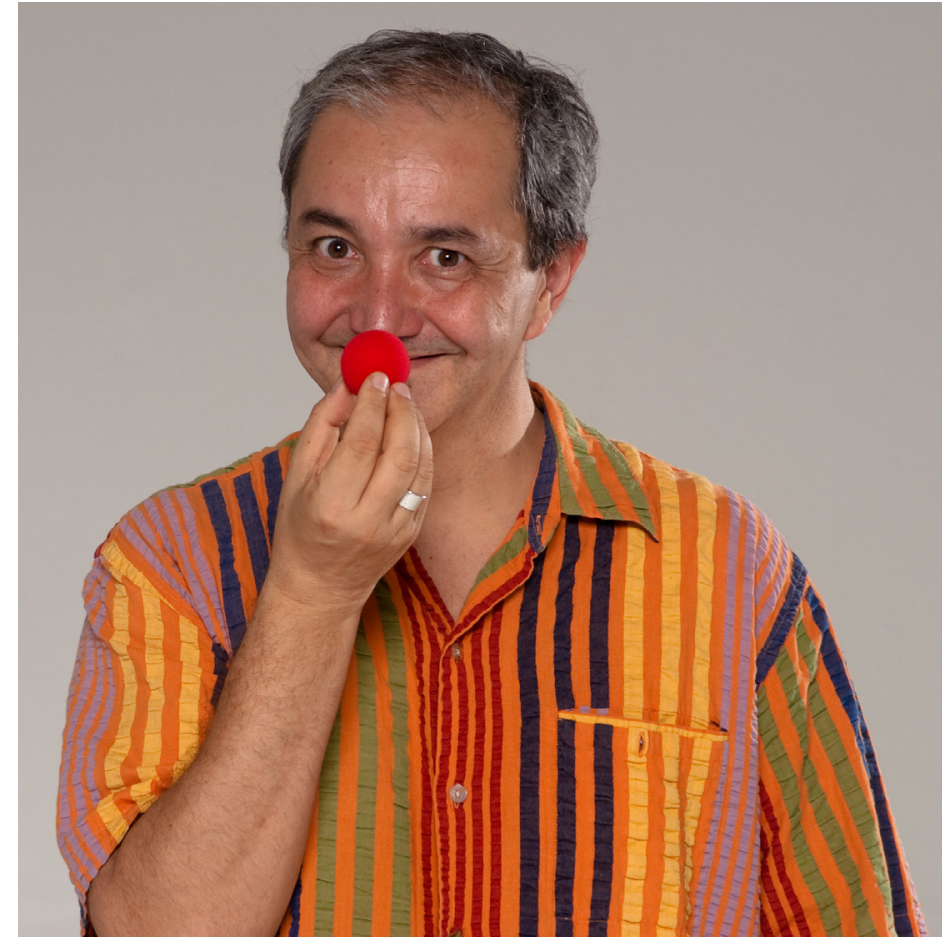

É fundador e coordenador geral do Doutores da Alegria - Arte, Formação e Desenvolvimento, organização ganhadora do "Prêmio Criança", outorgado pela Fundação Abrinq, três vezes reconhecida pela Divisão Habitat da ONU como uma das 40 Melhores Práticas Globais e também ganhadora do "Prêmio Cultura e Saúde", concedido em junho de 2009 pelo Programa Cultura Viva, iniciativa conjunta dos Ministérios da Cultura e Saúde.
RevMed: Como surgiu a iniciativa dos Doutores da Alegria? E sendo um projeto inédito e pioneiro no Brasil, houve resistência por parte dos hospitais ou mesmo dos próprios pacientes?

Conheci o trabalho em Nova York em 1988, através do Big Apple Circus Clown Care Unit; ao ver uma dupla de palhaços profissionais atuando no hospital, entendi a função social do artista e repensei toda minha relação com a arte, o trabalho.

Em 1991, meu pai ficou doente e voltei para vêlo; quando entrei no hospital, vi que não havia nenhum trabalho semelhante por aqui e, a pedido do meu pai, fiz um dia de trabalho como palhaço. Foi então que vi que o trabalho se traduzia muito bem. Assim, em setembro de 91, iniciei os Doutores da Alegria.

Após 21 anos, Doutores da Alegria é uma organização da sociedade civil, sem fins lucrativos, mantida pelo apoio de empresas e pessoas físicas na forma de patrocínio, parceria e associação. A organização foi pioneira na introdução da arte do palhaço em um quarto de hospital no Brasil. Desde 1991, seus palhaços já visitaram mais de 900 mil crianças e adolescentes hospitalizados.

RevMed: Qual a trajetória até a construção do projeto?

As visitas aos hospitais são um trabalho sistemático, com uma mesma dupla de palhaços visitando crianças de um mesmo hospital duas vezes por semana, durante um ano. Partimos da permissão de cada criança para construirmos uma história. São oito hospitais em São Paulo, quatro no Recife e três em Belo Horizonte. Nossas visitas não têm qualquer custo para o hospital ou para os pacientes e suas famílias. Todos os artistas do programa são remunerados através de recursos provenientes de patrocínio, doações, eventos, publicações, palestras e espetáculos.

Hoje, após 21 anos atuando nos hospitais, ampliamos nosso campo de atuação para várias atividades, divididas em quatro áreas:

Programa de hospitais - além do programa de vi- 
sitas, temos o Plateias Hospitalares, nos hospitais do Rio de Janeiro, e a Oficina Boas Misturas;

$>$ O Plateias Hospitalares é um programa singular e com grande aceitação nos hospitais cariocas. Neste caso, Doutores da Alegria seleciona grupos artísticos de diversas vertentes para que apresentem seus espetáculos dentro dos hospitais, com uma plateia diferente. Em três anos, já foram mais de 27 mil pessoas impactadas em oito hospitais da rede pública estadual;

> Criações artísticas - espetáculos, Rodas Besteirológicas, Espaço Cultural, Intervenções em empresas, workshops - a ampliação do trabalho a públicos que não estão nos hospitais;

$>$ Formação - Temos a Escola, que oferece cursos de formação na arte do palhaço para artistas, jovens de comunidades populares e público em geral, além de treinamentos e oficinas para grupos que atuam de forma semelhantes em outros hospitais do Brasil (Palhaços em Rede);

> Pesquisa - resultados e indicadores do trabalho nos hospitais.

RevMed: Quantos são os envolvidos atualmente? Existem grupos em outros estados ou então países?

A organização Doutores da Alegria está presente em São Paulo, Rio de Janeiro, Recife e Belo Horizonte e conta com uma equipe de 20 funcionários e colaboradores nas áreas administrativas e de formação, pesquisa, mobilização e cerca de 50 artistas que atuam hoje em 14 hospitais dessas localidades. Alguns dos artistas participam também da gestão da ONG.

Além da equipe de artistas "da casa", a organização articula, por meio de seu programa "Palhaços em Rede", uma rede com cerca de 630 grupos de atuação semelhante cadastrados - visitas aos hospitais - em todo o país.

O programa, criado em 2007, é uma forma atender a essa demanda de interessados na experiência dos Doutores da Alegria, compartilhar a metodologia de trabalho desenvolvida por meio da arte do palhaço e, principalmente, consolidar a causa da alegria aliada à ética e à qualidade das relações, que para a organização, são os pilares do trabalho nos hospitais.

Fora do Brasil, além do Big Apple Circus, há uma série de iniciativas bem-sucedidas de grupos de palhaços em hospitais, inclusive inspirando uma federação na Europa. É um movimento global e que tende a crescer cada vez mais.

RevMed: Como é a rotina dos Doutores da Alegria?

O Programa de Visitas do Doutores da Alegria tem um compromisso com a constância.

As visitas aos hospitais são um trabalho sistemático, com uma mesma dupla de palhaços visitando crianças de um mesmo hospital duas vezes por semana, seis horas por dia, durante um ano. Os artistas elaboram mensalmente um relatório que é enviado para os hospitais. Partimos da permissão de cada criança para construirmos uma história. Assim acreditamos levar às crianças hospitalizadas o melhor de nosso ofício de palhaços.

RevMed: Como são as oficinas? Qualquer um pode participar do projeto?

A Escola, que hoje abrange o núcleo de pesquisas dedicado à linguagem do palhaço, fonte de conhecimento e aprendizado constante para os 50 profissionais de seu elenco - e o núcleo de formação, oferece projetos e cursos direcionados a jovens, artistas profissionais e público em geral interessado em descobrir ou aprimorar a arte do palhaço. Vale destacar o Programa de Formação para Jovens (PFPJ), que já formou cerca de 200 jovens artistas para o mercado de trabalho desde seu início, em 2004. Os cursos, com exceção do Formação para Jovens, são todos pagos e servem para custear os diversos programas que a organização possui.

RevMed: Quais são os requisitos necessários para uma pessoa se tornar um Doutor da Alegria?

Para participar do processo seletivo para o elenco dos Doutores da Alegria, é necessário ser paIhaço profissional com DRT ou ator profissional com DRT e especialização na linguagem do palhaço.

Para a seleção dos artistas, existem três etapas: análise de currículos, oficinas, e teste no hospital. Os selecionados passam por um ano de treinamento, atuando uma vez por semana num hospital parceiro dos Doutores da Alegria acompanhados por um palhaço-treinador. Além disso, participam de um dia semanal de treinamento na sede para aprofundamento da linguagem do palhaço, ajustes de sua formação artística para o ambiente hospitalar, reforço de conceitos, exploração do universo hospitalar, criação em duplas/trios e desenvolvimento do besteirólogo. Uma vez por mês os novos palhaços participam de rodas artísticas junto com os veteranos para integração do grupo. 
O trabalho artístico não é voluntário porque trata-se de uma escolha. O constante desenvolvimento do artista é a sua subsistência e também a garantia de um trabalho cuidadoso, e de qualidade artística, seja para o teatro, o circo, a rua ou o hospital. A qualidade artística num palco ou num quarto de hospital deve ser a mesma. O trabalho nos Doutores da Alegria exige do artista disponibilidade mínima de dezoito horas semanais para as visitas sistemáticas aos hospitais e o desenvolvimento do seu repertório artístico, também aprimorado por cursos técnico e artístico. É um compromisso por um período de um ano que pode se renovar no ano seguinte, dependendo dos compromissos profissionais do artista e de sua adequação ao planejamento da organização.

\section{RevMed: Qual o principal objetivo do projeto?}

Somos uma organização da sociedade civil dedicada a promover a experiência da alegria junto a crianças hospitalizadas, seus pais e profissionais de saúde, por meio da arte do palhaço. Nossa missão é "Promover a experiência da alegria como fator potencializador de relações saudáveis por meio da atuação profissional de palhaços junto a crianças hospitalizadas, seus pais e profissionais de saúde. Compartilhar a qualidade desse encontro com a sociedade com produção de conhecimento, formação e criações artísticas."

RevMed: Quem são e quantos são os parceiros dos Doutores da Alegria?

Os parceiros dos Doutores estão divididos em empresas e pessoas físicas. Muitas empresas, como a White Martins, Wellstream e Sanofi, acabam patrocinando a organizações através de doações por meio das leis de incentivo Rouanet e Proac, entre outras, e podem divulgar suas logomarcas em jalecos e outros materiais da organização. Além desses parceiros, temos o programa "Sócios da Alegria", onde pessoas que fazem doações de recursos próprios ou por meio das leis de incentivo de forma única ou em caráter regular, e empresas que realizam parcerias eventuais (marketing relacionado à causa) ou apoios técnicos.

Além disso, as pessoas podem contribuir visitando a nossa loja virtual, assistindo a nossos espetáculos e participando de nossos eventos. Empresas podem contratar palestras e intervenções, como o "Riso 9000" e realizar uma campanha de marketing em parceria com os Doutores da Alegria.

No site: www.doutoresdaalegria.org.br/colabore é possível ver as formas de colaboração e os nossos patrocínios
RevMed: Como o senhor avalia a repercussão do projeto para as crianças e para quem está ao redor dessa criança?

O principal ingrediente é promover a experiência da alegria em um ambiente adverso, para crianças hospitalizadas, seus pais e profissionais de saúde, por meio da arte do palhaço, nutrindo esta forma de expressão como meio de enriquecimento da experiência humana.

O trabalho artístico profissional no ambiente hospitalar vem construindo ao longo desses anos uma parceria bem-sucedida entre artistas e profissionais de saúde. E aponta para alterações importantes com relação às crianças hospitalizadas: melhora no comportamento e na comunicação, maior colaboração com exames e tratamentos, diminuição da ansiedade com a internação, efeitos relatados por crianças, familiares e profissionais de saúde em pesquisa realizada por Morgana Masetti, posteriormente transformada no livro "Soluções de Palhaço - transformações na realidade hospitalar". Esses resultados são decorrentes da utilização do humor, de um sistema eficiente de comunicação e de um conjunto específico de valores e crenças sobre a realidade hospitalar.

No mês de outubro de 2008 apresentamos resultados de uma pesquisa realizada com 567 profissionais de saúde de hospitais onde atuamos em São Paulo e Rio de Janeiro. Estes resultados quantitativos fazem parte de um processo de avaliação qualitativa de três anos, iniciado em 2007, realizado pelo Instituto Fonte.

Os principais resultados e a metodologia desta pesquisa podem ser conhecidos no Balanço 2008 que está no nosso site www.douteresdaalegria.org.br

Os indicadores são extremamente importantes, pois eles mostram o cenário do nosso sistema de saúde, além de apontar as questões que necessitam ser aprimoradas, tanto em termos de trabalho para os Doutores quanto para o sistema em geral.

Temos também outras formas de compartilhar os resultados:

> Por meio da publicação anual de um Balanço de atividades;

> Por meio da disponibilização, para os doadores, dos relatórios de auditorias independentes (atualmente, contamos com a KPMG) realizados semestralmente;

> Publicação periódica (desde 1995) de pesquisas a respeito do impacto artístico do trabalho nos hospitais. 
RevMed: Como a sua história de vida, locais onde o senhor trabalhou e experiencias de vida contribuíram para a formação do projeto Doutores da Alegria?

Hmmmm.... Boa pergunta... Aos 42 anos eu passei por um processo chamado Biográfico, onde você olha sua vida como uma biografia e, nesse processo, me dei conta de que tudo o que fiz na vida, do jeito que fiz, minhas escolhas, tudo contribuiu para que eu escolhesse correr o risco de criar o Doutores; por exemplo, desde criança sou apaixonado por teatro, comédia, palhaços e música e na escola, era sempre eu o envolvido nas festas e comemorações; meu primeiro trabalho foi como professor de inglês, onde, desde a primeira aula, conquistei a confiança dos alunos com a comédia e as letras de música. Minha família me ensinou a cuidar do próximo e do coletivo, então, a soma de tudo isso tem um valor muito grande nessa história e me deu a coragem para optar por fazer acontecer. Nunca pensei nisso tão racionalmente como agora, pois tudo acontece comigo através da emoção, do prazer de materializar uma visão.

RevMed: O senhor mudou e continua mudando a vida de muitas crianças com o seu trabalho como o "Dr. Zinho" e elas de alguma forma mudaram a sua vida ou a sua percepção de vida?

Outra ótima pergunta! Sim, aprendi muito e continuo aprendendo com as crianças dentro e fora do hospital. Vi muita maturidade em crianças que estavam próximas da morte e nesse estado, abrirem espaço para uma visita nossa enquanto os adultos em volta pensavam: "talvez não seja uma boa hora para vocês virem aqui..." Essa capacidade de saber priorizar a alegria num momento único com esse, me impressiona. Não sei se eu teria essa sabedoria.

Some-se à isso a dignidade com que tantas crianças passam pelo sofrimento, sem auto-piedade $e$ com uma força natural, espontânea que é vulneravelmente forte, resiliente. Vivenciar essas experiências constantemente me ajudou a colocar as coisas em perspectiva e foi quando me abri para desfrutar a graça da vida. E abraçar sua simplicidade, as pequenas coisas... Minha vida é AD e DD, rsrs Antes dos Doutores e Depois dos Doutores.

RevMed: Quais foram as melhores lembranças que o senhor teve ou o que mais marcou nesses 21 anos de existência dos Doutores da Alegria? E as maiores dificuldades?

O dia em que visitei o hospital pela primeira vez com uma dupla de palhaços, as crianças no dia do meu teste, a reação das crianças aqui no Brasil, o reconhecimento do "Prêmio Criança" - como é importante ter o trabalho reconhecido em seu país! - cada hospital no qual iniciei o trabalho, os testes para seleção de artistas e, como não podia deixar de ser, as caras das crianças rindo e se divertindo. Brinco que tenho comigo uma coleção de momentos marcantes que guardo comigo na minha memória. Uma Quanto aos desafios, driblar a falta de conhecimento, tudo aquilo que impede as pessoas de reconhecerem a importância da alegria; como mensurar a alegria que sentimos e a sua importância na vida de qualquer ser humano? Como criar novas formas de mensurar e incluir alegria na vida de todo mundo, pois hoje em dia, não sei mais conde começa e onde termina o hospital; muitas doenças são cultivadas nas relações com a vida e uma resposta a tudo isso é o cultivo da cultura da alegria, quando saímos de nosso mundo para tornar melhor a vida de alguém e, consequentemente, nos tornando pessoas mais predispostas à alegria. Esse é meu desafio hoje! Mas, uma coisa aprendi: quanto mais eu disse sim para os desafios, mais minha vida ficou melhor.

RevMed: Antigamente, falar que sua profissão era de "palhaço de hospital" era visto com certo receio. Como que o publico lida com isso atualmente?

Hoje o palhaço que atua no hospital é um movimento global sem volta. E vários países, inclusive inspirados em nosso modelo de atuação, estão trabaIhando - cada vez mais em colaboração - para elevar essa prática à condição de profissão. Creio que hoje, temos cada vez mais pessoas interessadas nesse tipo de atuação, por isso criamos a nossa escola, para formar bons palhaços que atuem em hospitais e outros lugares onde seja necessário pensar o papel da alegria. O mais importante, é o que estamos fazendo com o programa palhaços em rede, é conscientizar todos que estão atuando na área da importância da formação, do cuidado com o paciente e as equipes de profissionais de saúde, do respeito às leis universais de higiene e saúde... Entrar no hospital como palhaço praticando a besteirologia não é uma coisa fácil, é preciso preparar-se com empenho. Porque, quanto mais difundido, mais necessidades temos de aprofundar conhecimento e trazer melhores soluções para o público dos hospitais. Não para nunca! Mas é divertido!

RevMed: Quais são as perspectivas futuras para os Doutores da Alegria?

Nestes mais de vinte anos de atuação, ficou mais que comprovado, para nós, o quanto a alegria é 
capaz de transformar ambientes e estimular relações saudáveis.

Assim, os Doutores da Alegria decidiram buscar mais e mais maneiras de ampliar o alcance de nossa missão, utilizando tudo o que aprendemos nos hospitais. Além dos diversos projetos já desenvolvidos pela organização, vamos reforçar nosso caráter pioneiro e de formador, ampliando espaço e compartilhando tecnologia para outros grupos de atuação semelhantes e outros artistas a também serem protagonistas deste movimento. A Escola é outro ponto de atenção, onde esperamos formar uma nova geração de artistas conscientes de seu papel e atuantes na realidade brasileira.

Esperamos que, como pingos n'água, nossas iniciativas gerem ondas em círculos cada vez mais abrangentes que carreguem em si a cultura da alegria, que nada mais é que a convicção de que é possível e necessário cultivar o bom-humor, a gentileza e a leveza até nas situações mais desafiadoras do nosso dia-a-dia. 